\title{
The care of individuals with substance misuse problems detained in police custody
}

\author{
Hamid Ghodse, Margaret Stark and Ralph Lawrence
}

Substance misuse is a substantial and growing problem. Forensic physicians are increasingly being asked by the police to assess substance misusers' fitness to be detained, the need for treatment and fitness for interview. Many substance misusers come into contact with the police either for drug offences or for offences committed to maintain their habit, such as shop-lifting and burglary, and $a$ forensic physician will then be called under the guidance given in the Codes of Practice 1991 of the Police and Criminal Evidence Act 1984 (1991).

January 1995 saw the publication of the Substance Misuse Detainees in Police Custody: Guidelines for Medical Management (DOH, 1995). It had been felt that a previous document Drug Misuse and DependenceGuidelines on Clinical Management, which was published in 1991 by the Department of Health (DOH, 1991), had not adequately covered the specific aspects of the management of substance misusers when detained in police custody.

The development of the new guidelines was initiated by the Association of Police Surgeons and, at the request of the Department of Health, a working party was convened in September 1993 by the Royal College of Psychiatrists. It included members of the relevant organisations including the Association of Police Surgeons, the Royal College of Psychiatrists, the Royal College of General Practitioners, and both the Faculty and the British Association for Accident and Emergency Medicine, with representatives from the Home Office and the Department of Health.

These guidelines are intended to supplement and amplify, but not replace, the earlier guidelines on clinical management. They pay particular attention to the aspects of management that are unique to the care of substance misusers in police custody.

The prevalence of substance misuse problems in the police cell population makes guidelines necessary for forensic physicians (police surgeons, forensic medical examiners, divisional surgeons) on acceptable minimum standards for the assessment of drug dependent individuals and for treatment intervention. Unless such guidelines are explicit and published, it will continue to be difficult to establish what constitutes good practice and whether good practice has or has not been followed in any particular instance.

These guidelines stress the rights of the detainee, in that the individuals in police stations are entitled to the same standard of medical care as any other member of the public. The forensic physician needs to give careful attention to the issue of consent of the detainee to any examination. Detainees have the right to have prescribed treatment continued while in custody, as long as it is clinically safe to do so.

The guidelines stress that a careful and well documented history and examination are essential to establish the degree of substance misuse and dependence. Studies have shown that substance misusers involved in maintenence programmes generally are honest when reporting drug use (Cox \& Longwell, 1974; Brown et al, 1992). The overall situation in police custody is unkmown, but honesty is more likely if the detainee feels confident of a sympathetic hearing and the availability of effective care. The overriding consideration of the attending doctor is the clinical safety and well-being of the detainee, so that prompt treatment to limit or prevent withdrawal symptoms is desirable; indications for prescribing substitute drugs 
are provided. However, treatment is not necessarlly the same as prescribing a substitute for the drug of dependence, though this may be the case and prescribing of certain drugs will occur when appropriate. Detainees should be informed of the outcome of the assessment and the consequent clinical decisions.

The possible impact of substance misuse intoxication and withdrawal states on the validity of a confession are discussed in a section on fitness for interview. In practice, intoxication states are less of a problem than withdrawal states. If the accused is obviously drunk or drugged when brought into the police station, then the police will be likely to wait until the intoxication has cleared before they begin their questioning. However, a person who is suffering from alcohol or drug withdrawal must be seen in some ways as especially vulnerable to giving a false confession. It is important that the forensic physician is aware of possible vulnerability factors. There may be certain factors for which the doctor can offer help such as counselling or reassurance. For example, if substance misusers are detained for any length of time, they can be reassured that their condition will be reviewed again by a doctor.

The guidelines summarise the requirements for notification and reporting of drug addicts and the relevant sections of the Mental Health Acts. Drug misuse and dependence alone are not sufficient grounds for compulsory admission to hospital under the Mental Health Acts nor for an appropriate adult to be present. The Home Office encourages the police service to form effective arrangements with local health services to ensure their speedy involvement when a person in custody is suspected of suffering from mental disorder. It will be useful for the forensic physician therefore to find out whether such links exist in their area as this will improve contacts with the psychiatric services.

Advice is given on intimate searches and on harm reduction for the substance misusers. Many drug misusers have little or no contact with doctors, and a visit by a forensic physician provides an opportunity to give advice on reducing the harm from continued drug misuse. There is practical advice on managing specific drug problems, for example, related to opioids and benzodiazepines.

The importance of liaison with other agencies is highlighted. The substance misuser, in addition to drug-related problems, may have other medical problems unrelated to drug misuse, for example, a recent head injury which require hospital treatment, (Ghodse, 1995). The forensic physician should ensure that concurrent problems are not overlooked because of a history of substance misuse/ dependence and liaise with appropriate colleagues (for example, accident and emergency department, obstetrician, medical team). Communication should preferably be both verbal and in writing.

This brief document cannot cover every situation that may arise in the police station. However, it provides guidance for the forensic physician in this problem area, and is sufficiently flexible to fit into the clinical practice of all forensic physicians. The principles which it endorses indicate good and adequate standards of care.

\section{References}

Brown, J., KranzaER, H. R. \& DEL BOCA, F. K. (1992) Self reports of alcohol and drug misuse in detainees: factors affecting reliability and validity. British Joumal of Addiction, 87, 1013-1024.

Cox. T. J. \& Longwru, B. (1974) Reliablity of interview data concerning current heroin use from heroin addicts on methadone. The International Journal of Addictions, 9. 161-165.

DePARTMENT OF HEALTH (1991) Drug Misuse and Dependence: guidelines on clinical management. London: HMSO.

- (1995) Substance Misuse Detainees in Police Custody: Guidelines for Medical Management. HMSO. Pp. 1-30.

GhoDse, A. H. (1995 2nd Edition.) Drugs and Addictue Behaviour, a guide to treatment. Oxford: Blackwell Scientific Publications.

Pouce AND Crnminl Evidence ACT 1984 (s.66) (1991) Codes of Practice. London: HMSO.

*Hamid Ghodse, Professor of Psychiatry and Addictive Behaviour, Hunter Wing, St George's Hospital Medical School Cranmer Terrace, London SW17 ORE; Margaret Stark, Forensic Physician, South London; and Ralph Lawrence, OBE. President of the Association of Police Surgeons, Derbyshire

"Correspondence 